\title{
Anatomical study of the location of the antilingula, lingula, and mandibular foramen for vertical ramus osteotomy
}

\author{
Jin Hoo Park, Hwi-Dong Jung, Hyung Jun Kim and Young-Soo Jung*
}

\begin{abstract}
Background: The purpose of this study was to identify the location of the antilingula, lingula, and mandibular foramen in Korean cadavers and to promote safe and accurate surgery without damage to the inferior alveolar neurovascular bundle (IANB) when performing a vertical ramus osteotomy (VRO).

Methods: This study was conducted on the dried mandibles of 20 adult cadavers. Digital calipers were used to measure the distances from the anatomical reference points (antilingula, lingula, and mandibular foramen).

Result: The antilingula was located at the anterior $44 \%$ and superior $31 \%$ in the ramus. The lingula was located at the anterior 55\% and superior 30\% in the ramus. The mandibular foramen was located at the anterior 58\% and superior $46 \%$ in the ramus. Regarding the positional relationship with the antilingula, the lingula was located 0.54 $\mathrm{mm}$ superior and $4.19 \mathrm{~mm}$ posterior, and the mandibular foramen was located $6.95 \mathrm{~mm}$ inferior and $4.98 \mathrm{~mm}$ posterior. The results suggested that in order to prevent damage to the IANB, osteotomy should be performed in the posterior region of ramus at least $29 \%$ of the total horizontal length of the ramus.
\end{abstract}

Conclusion: Using only the antilingula as a reference point is not guaranteed to IANB injury. However, it is still important as a helpful reference point for the surgeon in the surgical field.

Keywords: Antilingula, Lingula, Mandibular foramen, Vertical ramus osteotomy

\section{Background}

Vertical ramus osteotomy (VRO) is widely used for the surgical treatment of mandibular deformity [1]. VRO is an advantageous technique in that it is less likely to damage the inferior alveolar neurovascular bundle (IANB), but if this structure is damaged, it may lead to amputation of the IANB. However, there is also a disadvantage in that osteotomy cannot be performed by directly observing the location of the IANB from the medial side of ramus [2]. For the above reasons, the anatomical location of the IANB was the most important consideration for the surgeon in performing VRO, and long-term studies have been conducted to determine anatomical reference points to prevent damage to the IANB. Many previous studies have identified the

\footnotetext{
* Correspondence: ysjoms@yuhs.ac

Department of Oral and Maxillofacial Surgery, Yonsei University College of Dentistry, 50-1 Yonsei-ro, Seodaemun-gu, Seodaemoon-Gu, Seoul 120-752, South Korea
}

mandibular foramen, through which the IANB passes into the mandible, and the protruding anatomical structure that predicts the position of the lingula in front of the mandibular foramen, on the lateral side of the ramus; Yates named it the antilingula [3]. Several studies have since been conducted on the antilingula, lingula, and mandibular foramen [3-13].

Mandibular prognathism is a common maxillofacial deformity especially in East Asian populations, and treatment with VRO is effective in these cases [14]. However, no studies have been reported on direct measurement of such anatomical reference points in the mandibles of East Asian patients. This study attempted to locate the antilingula, lingula, and mandibular foramen by direct measurement of the East Asian mandible in order to reduce the risk of IANB injury, which may occur when performing VRO. Therefore, this study was to promote safe and accurate VRO. 


\section{Methods}

This study was conducted on the dried mandibles of 20 Korean adult cadavers with age and sex unknown and $<4$ missing teeth. All measurements were performed using a digital caliper fixed perpendicular to the platform, and the distances were measured from an anatomical measurement reference point up to $0.01 \mathrm{~mm}$. For accuracy, each measurement was performed by a measurer who majored in oral maxillofacial surgery. The measurement reference points were "antilingula," "lingula," and "mandibular foramen." Antilingula was the most prominent point on the lateral surface of the mandibular ramus and was confirmed by visual and tactile measurements. Lingula was the most superior point of the lingula, and mandibular foramen was the lowest point of the entrance of the IANB into the mandible. The measurement reference position was set to position 1 and position 2. Position 1 was the position wherein the lower margin of the mandible was placed on the platform, and position 2 was the position wherein the posterior point of the condyle and the posterior point of the mandibular were placed on the platform (Fig. 1). Measurements were made to determine distances A, B, C, and D. A was the distance between the line contacting the most concave point of the sigmoid notch and the anatomical measurement reference point parallel to the platform at position 1. B was the distance between the platform at position 1 and the anatomical measurement reference point. $\mathrm{C}$ was the distance between the line contacting the most concave point in the anterior of the ramus and the anatomical measurement reference point parallel to the platform at position 2. D was the distance between the line contacting the most concave point of the posterior of the ramus and the anatomical measurement reference point parallel to the platform at position 2 (Fig. 2). The mean and standard deviation of the distances (A, B, C, D), and the mean, standard deviation, maximum value, and minimum value of the distances between the antilingula and the other two anatomical measurement reference points were obtained. Pearson correlation coefficients were used to examine the correlations. The position of each anatomical reference point in the ramus was calculated as a ratio of the total length, and the mean, standard deviation, and maximum and minimum values were obtained. Statistical analysis was performed using Statistical Package for Social Sciences for Windows (version 22.0, SPSS, Chicago, IL, USA).

\section{Results}

The antilingula was located an average of $14.61 \mathrm{~mm}$ $(S D=3.74)$ inferior from the sigmoid notch and $14.71 \mathrm{~mm} \quad(\mathrm{SD}=1.63)$ posterior from the anterior border of the ramus. The lingula was located an average of $14.06 \mathrm{~mm}(\mathrm{SD}=3.05)$ inferior from the sigmoid notch and $18.89 \mathrm{~mm}(\mathrm{SD}=1.91)$ posterior from the anterior border of the ramus. The mandibular foramen was located an average of $21.56 \mathrm{~mm}(\mathrm{SD}=2.31)$ inferior from the sigmoid notch and $19.69 \mathrm{~mm}(\mathrm{SD}=2.22)$ posterior from the anterior border of the ramus (Table 1).

From the antilingula, the lingula was located $0.54 \mathrm{~mm}$ $(\mathrm{SD}=2.87)$ superior from the sigmoid notch and $4.19 \mathrm{~mm}(\mathrm{SD}=2.25)$ posterior from the anterior border of the ramus. The maximum distances to the superior, inferior, anterior, and posterior sides were 6.24, 4.88, 0.12, and $9.14 \mathrm{~mm}$, respectively. From the antilingula, the mandibular foramen was located $6.95 \mathrm{~mm}(\mathrm{SD}=3.11)$ inferior from the sigmoid notch and $4.98 \mathrm{~mm}(\mathrm{SD}=2.38)$ posterior from the anterior border of the ramus. The minimum and maximum distances to the inferior side were 1.04 and $12.86 \mathrm{~mm}$, respectively, and the minimum and maximum distances to the posterior side were 0.16 and $12.86 \mathrm{~mm}$, respectively (Table 2). Statistically, the antilingula and lingula $(r=0.659, p<0.01)$ and the antilingula and mandibular foramen $(r=0.659, p<0.01)$ exhibited moderate vertical correlations. However, the horizontal correlations between the antilingula and lingula $(r=0.202, p=0.211)$, and the antilingula and mandibular foramen $(r=0.262, p=0.102)$ were weak and statistically insignificant (Table 3 ).

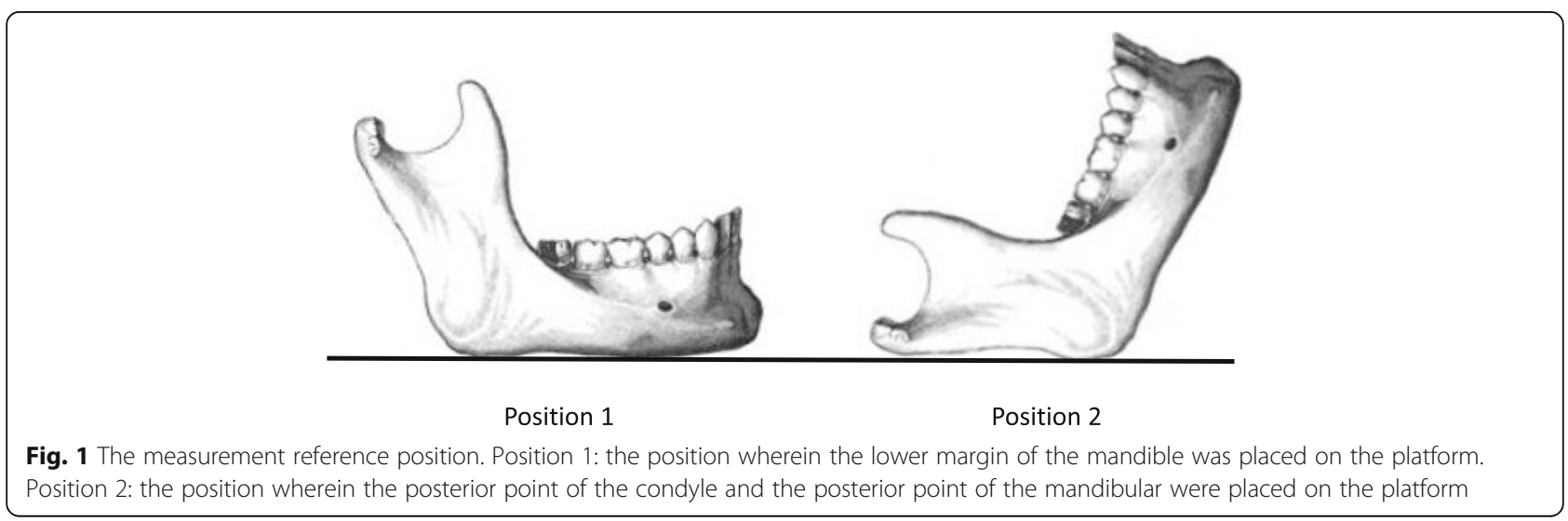



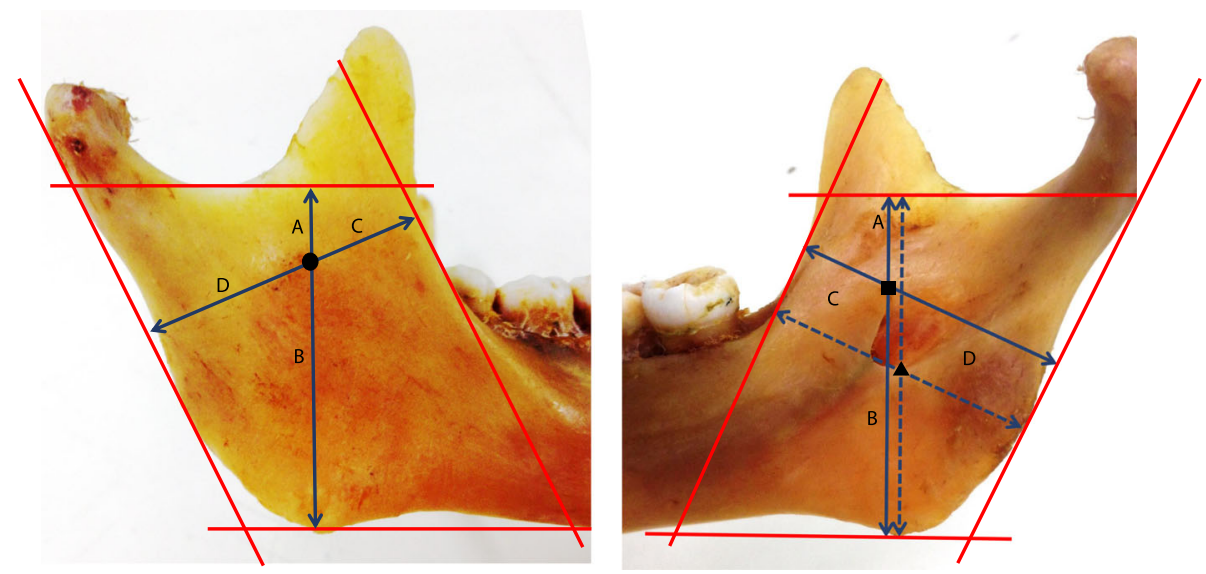

Fig. 2 Antilingula (circle), lingula (square), and mandibular foramen (triangle) measurement. Antilingula: the most prominent point on the lateral surface of the mandibular ramus. Lingula: the most superior point of the lingual. Mandibular foramen: the lowest point of the entrance of the IANB into the mandible

With regard to the ratio of each measurement reference point to the border of the ramus, the antilingula was $56 \%(\mathrm{SD}=4 \%)$ horizontal from the posterior border of ramus, and $31 \%(\mathrm{SD}=6 \%)$ vertical from the sigmoid notch. The lingula was $45 \%(\mathrm{SD}=5 \%)$ horizontal from the posterior border of the ramus, and $30 \%(\mathrm{SD}=5 \%)$ vertical from the sigmoid notch. The mandibular foramen was $42 \%(\mathrm{SD}=6 \%)$ horizontal from the posterior border of the ramus, and $46 \%(\mathrm{SD}=4 \%)$ vertical from the sigmoid notch. The lowest values of the anteroposterior and superoinferior ratios of the antilingula were 36 and $48 \%$, and 20 and 56\%, respectively. The lowest values of anteroposterior and superoinferior ratios of the lingula were 46 and $38 \%$, and 23 and 51\%, respectively. The lowest values of the anteroposterior and superoinferior ratios of the mandibular foramen were 29 and $47 \%$, and 37 and $47 \%$, respectively (Fig. 3).

\section{Discussion}

Damage to the IANB during orthognathic surgery on the mandibular ramus is a major complication that can be avoided. To prevent this complication, there have been

Table 1 Mean value (M) and standard deviation (SD) for each anatomic point

\begin{tabular}{llllll}
\hline \multirow{2}{*}{ Anatomic point } & & \multicolumn{3}{l}{ Measurement } \\
\cline { 3 - 6 } & & $\mathrm{A}$ & $\mathrm{B}$ & $\mathrm{C}$ & $\mathrm{D}$ \\
\hline Antilingula & Mean $(\mathrm{mm})$ & 14.61 & 32.12 & 14.71 & 18.59 \\
& $\mathrm{SD}$ & 3.74 & 3.38 & 1.63 & 1.82 \\
Lingula & Mean $(\mathrm{mm})$ & 14.06 & 32.36 & 18.89 & 18.89 \\
& $\mathrm{SD}$ & 3.05 & 3.49 & 1.91 & 1.91 \\
Mandibular foramen & Mean $(\mathrm{mm})$ & 21.56 & 25.18 & 19.69 & 14.41 \\
& $\mathrm{SD}$ & 2.31 & 3.59 & 2.22 & 2.32 \\
\hline
\end{tabular}

several attempts to develop novel surgical techniques to avoid damage to the IANB during osteotomy of the lateral side of the ramus, such as VRO, inverted L-osteotomy, and C-shaped osteotomy. In order to identify the theoretical basis of these surgical techniques, there have been many studies to determine the anatomical location of the IANB in the lateral side of ramus [3-6, 8-12].

The antilingula is an elevated part of the lateral side of the ramus that was previously described as a prominence [1], bump [15], or tubercle [16]. Yates et al. [3] referred to this structure as the antilingula and were the first to report a relationship with the mandibular foramen. In subsequent years, research on the antilingula was conducted as an anatomical measurement reference point for mandibular surgery. In a study by Yates et al. [3] using 70 dry mandibles, the antilingula was found in $44 \%$, indefinitely found in $41 \%$, and could not be found in $15 \%$. Yates claimed that the antilingula was a highly variable anatomical landmark, but that the posterior $5 \sim 10 \mathrm{~mm}$ of the antilingula was a statistically safe area. Pogrel et al. [6] found the antilingula in all cases in a study of mandibles in 20 cadavers; in most cases, the lingula was present in the posteroinferior region of the antilingula. Aziz et al. [8] found the antilingula in all cases in a study of mandibles in 18 cadavers. The lingula was present in the anterior, posterior, superior, and inferior regions of the antilingula, but there was "no risk of damaging the neurovascular bundle" during osteotomy in the posterior $5 \mathrm{~mm}$ of the antilingula.

Recently, studies investigating Asian populations have also been introduced. In a study by Apinhasmit et al. [9] using 92 dry mandibles, the antilingula was found in $80.4 \%$ of the patients, and it was confirmed that the antilingula was primarily present in the anterior-inferior region of the lingula. In a study by Hosapatna et al. [12] 
Table 2 Mean value (M), standard deviation (SD), maximum (Max), and minimum (Min) value for difference between antilingula and other point

\begin{tabular}{|c|c|c|c|}
\hline \multirow[b]{2}{*}{ Anatomic point } & & \multicolumn{2}{|l|}{ Measurement } \\
\hline & & $\bar{A}$ & C \\
\hline \multirow[t]{3}{*}{ Antilingula and lingula } & Mean $(\mathrm{mm})$ & +0.54 & +4.19 \\
\hline & SD & 2.87 & 2.25 \\
\hline & Max./Min & $+6.24 /-4.88$ & $+0.12 /-9.14$ \\
\hline \multirow[t]{3}{*}{ Antilingula and mandibular foramen } & Mean $(\mathrm{mm})$ & -6.95 & +4.98 \\
\hline & SD & 3.11 & 2.38 \\
\hline & Max./Min & $-1.04 /-12.86$ & $-0.16 /-9.06$ \\
\hline
\end{tabular}

At " $A$ " difference measurement, positive value means that antilingula inferior to other points and negative value means that antilingula superior to other points. At " $\mathrm{C}$ " difference measurement, positive value means that antilingula anterior to other points and negative value means that antilingula posterior to other points)

using 50 South Indian dry mandibles, it was confirmed that the mandibular foramen existed in the posterosuperior region of the antilingula, in contrast to the findings of previous studies. In the present study, the lingula was present in posterosuperior region of the antilingula. Although the difference in the superior side was $0.54 \mathrm{~mm}$, which was not significant, this was slightly different from previous studies. On the other hand, the mandibular foramen was found to be present in the posteroinferior region of the antilingula. This is a similar pattern with most existing studies.

The East Asian populations have more cases of mandibular prognathism than other races, and VRO can be useful in this case [14]. However, the anatomical studies of the mandibular ramus have been conducted mainly on Caucasian populations, and have been carried out in Southeast Asian, and Indian patients. In contrast, cases of direct measurement of the mandible in East Asian populations are not common. In this respect, the present study is meaningful.

As much as the interest in Antilingula, a controversy was raised. In a study by Reitzik et al. [4], in addition to antilingula, anatomical points termed the "midpoint of the waist of the ascending ramus" (MW) and the "midpoint of a line joining the coronoid process to the gonion" (MCG) were identified. The study reported that the MW was the most useful among the three anatomical points. Martone et al. [5] insisted that no antilingula was present and that the MW was the surgical reference point. Park et al. [11] used three-dimensional CT to study 25 patients with normal class 1 occlusion, 50 patients with mandibular prognathism, and 50 patients with mandibular retrognathism. The antilingula was clinically identifiable in 46.7, 44.4, and $45.3 \%$ of cases, and the MW was reported to be an excellent intraoperative reference point. Hogan and Ellis [17] reported that the antilingula is not an anatomical marker associated with the mandibular foramen and is not appropriate as a surgical guide for osteotomy because it is a musculotendinous apparatus. In a study by Monnazzi et al. [10] using 44 dry mandibles, antilingula was not recommended for use as a VRO landmark. In the present study, we found the antilingula in all subjects, but the use of antilingula alone as an anatomical reference point is not believed to prevent damage to the IANB.

There were several considerations when defining the anatomical measurement points in this study. In some studies, the antilingula was not observed, and it was thought that there was difficulty in setting the antilingula $[3,5,6,9,12]$. However, our study demonstrated that the antilingula was the most prominent part of the lateral side of the ramus, which was found by both visual and palpation methods, and was observed on both sides of the mandible (40 sites) in 20 cadavers. In the setting of the mandibular foramen, in order to safely preserve the IANB, the measurement point must be set behind the most posterior border of the mandibular foramen. However, the posterior border of the mandibular foramen is not clear. In this study, the accuracy and consistency of the measurements are maintained, as a relatively objective land mark, which is the most inferior point of mandibular foramen. The lingula was relatively clear, and there was no difficulty in setting up the point lingula.

Recently, the development of imaging technology such as CT has aided in confirming and measuring the course of the IANB in the preoperative plan $[11,18,19]$. However, in order for the surgeon to perform exactly the planned operation, it is necessary to know the accurate structure of the mandible to lower the risk of surgery, and information on the anatomical structures that can

Table 3 Correlation among the measurements between the antilingula, lingula, and mandibular foramen

\begin{tabular}{|c|c|c|c|c|c|}
\hline$r$ & Lingula & Mandibular foramen & & Lingula & Mandibular foramen \\
\hline Antilingula (vertical) & $0.659^{* *}$ & $0.559^{* *}$ & Antilingula (horizontal) & 0.202 & 0.262 \\
\hline
\end{tabular}

Pearson correlation analysis: ${ }^{* *} p<0.01$ 

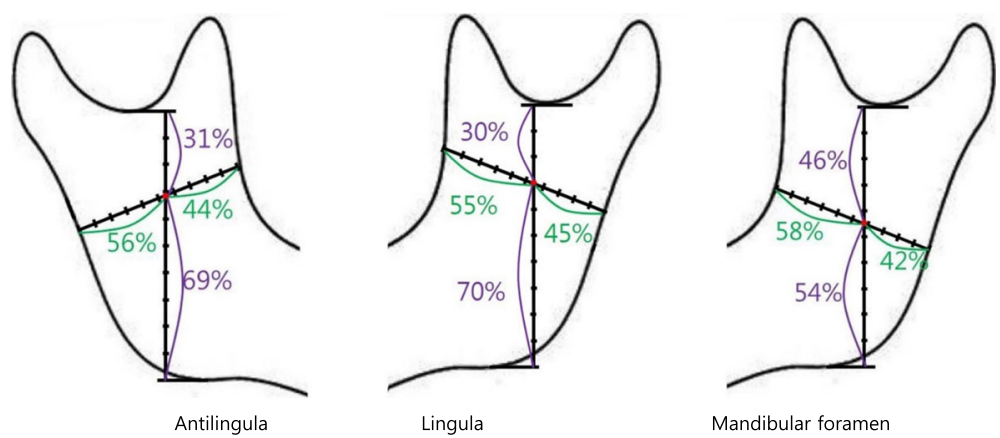

Fig. 3 Average position of anatomic point on ramus. Minimum value from border of ramus. Anterior- $\boldsymbol{A}$, posterior- $\boldsymbol{P}$, superior- $\boldsymbol{S}$, and inferior- $\boldsymbol{I}$. Antilingula $\boldsymbol{A}: 36 \%, \boldsymbol{P}: 48 \%$, S: 20\%, I: 56\%. Lingula $\boldsymbol{A}: 46 \%, \boldsymbol{P}: 38 \%$, S: $23 \%, \boldsymbol{I}: 51 \%$. Mandibular foramen $\boldsymbol{A}: 29 \%, \boldsymbol{P}: 47 \%, \boldsymbol{S}: 37 \%, \boldsymbol{I}: 47 \%$

be directly observed in the surgical field are needed. Because the mandibular foramen and lingula are difficult to visually identify when performing VRO, the structure must be recognized by the surgeon. The antilingula is the most prominent part of the lateral side of the ramus and is easy to observe, even if this region does not define the exact position of the mandibular foramen, it can be highly useful as a reference point for the entire ramus.

\section{Conclusions}

According to the results of this study, the surgical safe region, which we propose for safe and accurate surgery in order to prevent damage to the IANB during VRO, is $29 \%$ posterior region of the total horizontal length of the ramus, 37\% superior region of total height of ramus from sigmoid notch to inferior border. Numerically, this region is posterior region more than $9.02 \mathrm{~mm}$ from the posterior border of the ramus and superior region more than $17.86 \mathrm{~mm}$ from the sigmoid notch.

The current study used mandibles from only 20 cadavers; therefore, further studies will be needed in the future. Additionally, due to the different anatomical characteristics of each individual, it is important to identify the anatomy of the patient via preoperative imaging to avoid damage during surgery.

Furthermore, when the antilingula alone is used as a reference point, prevention of damage to the IANB cannot be guaranteed. However, the antilingula is still important as a reference point for the surgeon in the surgical field. By locating the antilingula in the ramus, the surgeon may be able to approximate the overall anatomy of the ramus during surgery.

\section{Abbreviations}

IANB: Inferior alveolar neurovascular bundle; VRO: Vertical ramus osteotomy

Availability of data and materials

Data and material sharing is applicable to this article.

\section{Authors' contributions}

$J H P, H-D J, H J K$, and Y-SJ were responsible for the conception and design of the study/review/case series, and drafting and critical revision of the article. JHP was responsible for the acquisition of the data, laboratory or clinica//literature search and analysis and interpretation of the data collected. All authors read and approved the final manuscript.

\section{Ethics approval and consent to participate}

Not applicable. This study was conducted on the dried mandibles of 20 Korean adult cadavers with age and sex unknown. Cadavers, autopsy specimens, or specimens/information from subjects who are now deceased are not "human subjects."

\section{Consent for publication}

Not applicable.

\section{Competing interests}

The authors declare that they have no competing interests.

\section{Publisher's Note}

Springer Nature remains neutral with regard to jurisdictional claims in published maps and institutional affiliations.

Received: 29 May 2018 Accepted: 18 June 2018

Published online: 25 July 2018

\section{References}

1. Caldwell JB, Letterman GS (1954) Vertical osteotomy in the mandibular rami for correction of prognathism. J Oral Surg (Chic) 12:185-202

2. Zaytoun HS, Phillips C, Terry BC (1986) Long-term neurosensory deficits following transoral vertical ramus and sagittal split osteotomies for mandibular prognathism. J Oral Maxillofac Surg 44:193-196

3. Yates C, Olson D, Guralnick W (1976) The antilingula as an anatomic landmark in oral surgery. Oral Surgery, Oral Medicine, Oral Pathology 41:705-708

4. Reitzik M, Griffiths RR, Mirels H (1976) Surgical anatomy of the ascending ramus of the mandible. British Journal of Oral Surgery 14:150-155

5. Martone CH, Ben-Josef AM, Wolf SM, Mintz SM (1993) Dimorphic study of surgical anatomic landmarks of the lateral ramus of the mandible. Oral Surgery, Oral Medicine, Oral Pathology 75:436-438

6. Pogrel MA, Schmidt BL, Ammar A (1995) The presence of the antilingula and its relationship to the true lingula. Br J Oral Maxillofac Surg 33:235-238

7. da Fontoura RA, Vasconcellos HA, Siqueira Campos AE (2002) Morphologic basis for the intraoral vertical ramus osteotomy: anatomic and radiographic localization of the mandibular foramen. J Oral Maxillofac Surg 60:660-665

8. Aziz SR, Dorfman BJ, Ziccardi VB, Janal M (2007) Accuracy of using the antilingula as a sole determinant of vertical ramus osteotomy position. J Oral Maxillofac Surg 65:859-862

9. Apinhasmit W, Chompoopong S, Jansisyanont P et al (2011) The study of position of antilingula, midwaist of mandibular ramus and midpoint between coronoid process and gonion in relation to lingula of 92 Thai 
dried mandibles as potential surgical landmarks for vertical ramus osteotomy. Surg Radiol Anat 33:337-343

10. Monnazzi MS, Passeri LA, Gabrielli MFR, Bolini PDA, de Carvalho WRS, da Costa Machado H (2012) Anatomic study of the mandibular foramen, lingula and antilingula in dry mandibles, and its statistical relationship between the true lingula and the antilingula. Int J Oral Maxillofac Surg 41:74-78

11. Park K-R, Kim S-Y, Kim G-J, Park H-S, Jung Y-S (2014) Anatomic study to determine a safe surgical reference point for mandibular ramus osteotomy. J Cranio-Maxillofac Surg 42:22-27

12. Hosapatna M, Ankolekar VH, D'Souza AS, Deepika C, D'Souza A (2015) The study of antilingula and its relation to the lingula and mandibular foramen, the presence of mylohyoid bridging in dry mandibles of South Indian population. Journal of Maxillofacial and Oral Surgery 14:308-311

13. Zhou C, Jeon T-H, Jun S-H, Kwon J-J (2017) Evaluation of mandibular lingula and foramen location using 3-dimensional mandible models reconstructed by cone-beam computed tomography. Maxillofacial Plastic and Reconstructive Surgery 39:30

14. Baik HS, Han HK, Kim DJ, Proffit WR (2000) Cephalometric characteristics of Korean Class III surgical patients and their relationship to plans for surgical treatment. The International journal of adult orthodontics and orthognathic surgery 15:119-128

15. Behrman S (1974) Complications associated with orthognathic surgery. In: Current advances in oral surgery. Mosby, St Louis, MO, pp 109-143

16. Hall HD, Chase DC, Payor LG (1975) Evaluation and refinement of the intraoral vertical subcondylar osteotomy. Journal of oral surgery (American Dental Association : 1965) 33:333-341

17. Hogan G, Ellis E (2006) The "antilingula"—fact or fiction? J Oral Maxillofac Surg 64:1248-1254

18. Tsuji Y, Muto T, Kawakami J, Takeda S (2005) Computed tomographic analysis of the position and course of the mandibular canal: relevance to the sagittal split ramus osteotomy. Int J Oral Maxillofac Surg 34:243-246

19. Fujimura K, Segami N, Kobayashi S (2006) Anatomical study of the complications of intraoral vertico-sagittal ramus osteotomy. J Oral Maxillofac Surg 64:384-389

\section{Submit your manuscript to a SpringerOpen ${ }^{\circ}$ journal and benefit from:}

- Convenient online submission

- Rigorous peer review

- Open access: articles freely available online

- High visibility within the field

- Retaining the copyright to your article

Submit your next manuscript at $\boldsymbol{s p r i n g e r o p e n . c o m ~}$ 